\title{
Costumbre mercantil en el sector inmobiliario: su aplicación en materia de arrendamiento de local comercial
}

\section{Commercial practice in the property sector: its application in the leasing of commercial property.}

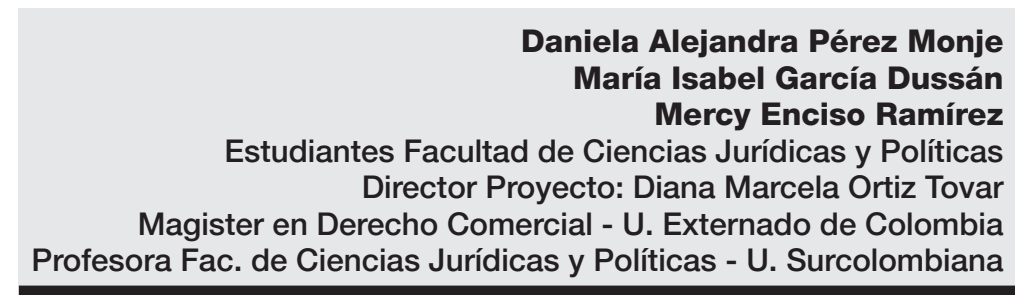

dmortizto@yahoo.com

«Lo que acostumbramos a llamar instituciones necesarias, muchas veces son instituciones a las que nos hemos acostumbrado».

Alexis Tocqueville

\section{RESUMEN}

Teniendo en cuenta que la principal forma de regular las relaciones sociales es la ley y que a pesar de la amplia gama normativa existente en la legislación colombiana aún quedan vacíos legales, se hace necesario recurrir a otras fuentes del derecho como la costumbre para lograr claridad y certeza en el desarrollo de ciertas actividades.

Dentro de los grupos poco regulados por la normatividad colombiana se encuentra el sector inmobiliario, que ha visto necesario acudir a la costumbre mercantil como fuente de derecho, para que a través de su interpretación, integración y creación se suplan los vacíos respecto a las actividades que el sector desarrolla; permitiendo con ello establecer las reglas generales, por las cuales se rige la actividad inmobiliaria.

Al tener las Cámaras de Comercio la potestad de certificar las Costumbres Mercantiles que se practican en aquellos lugares que correspondan a su jurisdicción, se ha iniciado esta investigación para abordar las costumbres mercantiles existentes en la actividad inmobiliaria de las ciudades de Neiva, Pitalito y Garzón en relación con la intermediación en el arrendamiento de local comercial y el canon de arrendamiento a cobrar, para así determinar si éstas cumplen con los requisitos exigidos por el código de comercio para su validez y aplicación.

\section{PALABRAS CLAVE}

Costumbre mercantil, sector inmobiliario, intermediación, arrendamiento de local comercial, canon de arrendamiento.

\section{ABSTRACT}

Given that the main way of regulating social relations is the law and that despite the wide range of regulations that we have in our country there are still loopholes, it is necessary to resort to other sources of law like the custom to achieve clearly and certainty in the development of certain activities.

Inside groups poorly regulated by Colombian laws is the real estate that has seen necessary to resort to commercial custom, as a source of law, so that through its interpretation, integration and creation the real 
estate can provided gaps about activities that sector develops, thus allowing to establish general rules, which is govern the property business.

The Chambers of Commerce have the power to issue certificates in respect of Commercial Custom that are practiced in those places under its jurisdiction, this research has been started to address the existing commercial customs in the real state agency business in the cities of Neiva, Pitalito and Garzón in relation with the intermediation in leasing commercial space and the canon of lease receivables, to determine whether they meet the requirements of the commercial code for their validity and application.

\section{KEYWORDS}

Custom Commercial, Sector Real Estate, Brokerage, Leasing business premises, rent.

\section{INTRODUCCIÓN}

La ley es una de las principales normas que pertenecen al ordenamiento jurídico y la Constitución la reconoce como fuente válida de derecho. La ley a su turno admite y autoriza a la costumbre jurídica (Ley 153 de 1887, art. 13; C de Co art 3; C de P C art. 189) con las limitaciones que ella establece, como fuente de derecho. Es la invocación que la ley hace de la costumbre la que reafirma su pertenencia al sistema jurídico y su naturaleza normativa.

Ahora bien, en el derecho privado, la costumbre ha sido acogida de forma exclusiva; en materia civil y comercial la costumbre cumple una función de vital importancia para el tráfico jurídico, y el carácter dispositivo de gran parte del ordenamiento legal permite concluir que la costumbre y las estipulaciones contractuales son consecuencia de la libertad económica y de la iniciativa privada, garantizadas constitucionalmente, y su exigibilidad judicial se torna imperativa en virtud del interés social de un intercambio económico transparente y fluido y de la racionalización de la economía (CP. arts. 333 y 334).

De hecho, la costumbre mercantil, podrá aplicarse cuando así se requiera y tendrá el mismo poder vinculante de la ley siempre que cumpla con los requisitos que ésta exige para que una práctica se considere como tal generando seguridad jurídica. Una forma de dar certeza sobre la existencia de las prácticas reiteradas, uniformes, obligatorias, vigentes en una comunidad es la certificación que emiten las Cámaras de Comercio en aquellos lugares que corresponda conforme a su jurisdicción, ya que es la entidad encargada de la regulación de la Costumbre Jurídica Mercantil, generando como resultado su preferente aplicación, salvo que la misma ley mercantil de forma expresa invoque la regulación de la ley civil.

En la práctica las inmobiliarias, con base en la necesidad de establecer unos pilares para desarrollar sus actividades y ante la falta de regulación normativa de este importante sector de bienes y servicios, mediante una serie de hechos y circunstancias han establecido las formas de definir y determinar ciertos aspectos especialmente en el campo de arrendamiento de locales comerciales, de tal manera que se encontró necesario realizar un análisis de los usos y las prácticas no regulados por la ley que se llevan a cabo por las inmobiliarias, específicamente aquellos relacionados con la estipulación del valor del canon de arrendamiento de locales comerciales, el término empleado por la inmobiliaria para el respectivo pago al propietario del inmueble, el valor (\%) de la comisión por la intermediación y la exigencia 0 no de la constitución de un seguro inmobiliario, de ahí que el problema de investigación está dirigido a determinar: ¿Cuáles son las costumbres mercantiles de las inmobiliarias de la ciudad de Neiva, Pitalito y Garzón en relación con la intermediación de arrendamiento de local comercial y la determinación del canon de arrendamiento a cobrar?

Teniendo en cuenta la problemática que se abordó, el enfoque epistemológico más conveniente para desarrollar la investigación fue el de carácter 
cuantitativo descriptivo, pues comprende por una parte una amplia revisión teórica de doctrina y jurisprudencia sobre el derecho comercial, la costumbre como fuente de derecho y la costumbre mercantil en el sector inmobiliario; mediante la aplicación de instrumentos con preguntas de selección múltiple con única respuesta, como mecanismo de recolección de datos, recurriendo a la estadística para tabular la información recolectada, se empleó la inferencia inductiva y se hizo un estudio concreto de los datos en su evolución y transformación a través del tiempo.

En razón de lo anteriormente mencionado, se trazó como objetivo general de la investigación determinar si las costumbres mercantiles de las inmobiliarias de la ciudad de Neiva, Garzón, Pitalito y la Plata, en relación con la intermediación en el arrendamiento de local comercial y la determinación del canon de arrendamiento a cobrar, cumplen con los requisitos exigidos por el código de comercio para su validez y aplicación; y a su vez se propusieron como objetivos específicos: 1) identificar los mecanismos establecidos por las inmobiliarias para fijar el valor del canon de arrendamiento del local comercial; 2) identificar el término utilizado por los agentes inmobiliarios o comisionistas para el pago del canon de arrendamiento al propietario del local comercial arrendado; 3) determinar el valor de la comisión por la intermediación en el arrendamiento de local comercial de acuerdo a las modalidades establecidas para local comercial; 4) establecer si la constitución del seguro inmobiliario se tiene para garantizar el pago del canon de arrendamiento del local comercial al propietario del mismo en caso de incumplimiento por parte del arrendatario; 5) analizar si los usos mercantiles derivados de la actividad inmobiliaria en los aspectos señalados son uniformes, reiterados, públicos, obligatorios y vigentes. La novedad y el aporte de la presente investigación es servir como apoyo tanto a las inmobiliarias como a los arrendadores y arrendatarios de locales comerciales. A las primeras, en relación con la certeza de lo contenido en los contratos de arrendamiento de locales comerciales suscritos en la relación contractual; y a los segundos, en el establecimiento claro y completo de la normatividad y pautas que rigen sus actuaciones, llenando cualquier vacío normativo y evitando que se presenten dudas insuperables 0 algunas ambigüedades que no permitan desplegar una adecuada y correcta aplicación de las prácticas inmobiliarias.

\section{DESARROLLO DEL TEMA}

Se realizó de manera previa a la estructuración del proyecto, un estudio exploratorio, con el cual, se logró establecer y analizar el desarrollo de las labores de las entidades dedicadas al sector inmobiliario, identificando los campos específicos de las prácticas que nos llevaron a concluir como posibles costumbres mercantiles, a saber: 1) el valor del canon de arrendamiento del local comercial fijado por la inmobiliaria; 2) el término utilizado por los agentes inmobiliarios o comisionistas para el pago del canon al propietario del bien inmueble; 3) el valor de la comisión por la intermediación en el arrendamiento de acuerdo a las modalidades establecidas para local comercial; y 4) la constitución del seguro inmobiliario para garantizar el pago del arriendo al propietario en caso de incumplimiento por parte del arrendatario en el pago de éste.

Con base en el cronograma de actividades planteado en el proyecto de investigación, se inició la ejecución haciendo una revisión bibliográfica respecto del derecho comercial, la costumbre como fuente de derecho y la costumbre mercantil inmobiliaria, recopilándose información doctrinal y jurisprudencial; de igual manera se procedió a elaborar un instrumento, medio básico para la recolección de información del tema de investigación, que se aplicó inicialmente como prueba piloto a tres inmobiliarias, tomadas al azar de la base de datos otorgada por la Cámara de Comercio de Neiva. Cabe mencionar que el instrumento (encuesta) usado para la recolección de datos se estructuró con preguntas de selección múltiple con única respuesta pues se consideró como el sistema más acertado para indagar sobre los aspectos relevantes de las prácticas comerciales objeto de estudio. 
Igualmente se llevó a cabo una salida de campo que consistió en la aplicación del mismo a las inmobiliarias matriculadas en la Cámara de Comercio de Neiva que desarrollan la actividad de intermediación y/o administración en el arrendamiento de locales comerciales en las ciudades de Neiva, Pitalito y Garzón. La base de datos suministrada por la entidad indicaba un total de sesenta y tres (63) inmobiliarias ubicadas en las ciudades objeto de estudio; pero al corroborar la información para programar las visitas a estas agencias para la posterior aplicación del instrumento, se evidenció que realmente existían doce (12) inmobiliarias en la ciudad de Neiva, cuatro (4) en el municipio de Pitalito y una (1) en el municipio de Garzón, debido a que la mayoría habían desaparecido del mercado, se habían trasladado a otras ciudades o simplemente la dirección no existía o de existir correspondía a otro tipo de negocio. Finalmente, de las diecisiete (17) inmobiliarias que realmente se encontraron en los municipios en mención, solo catorce (14) tienen incorporada la modalidad de arrendamiento de local comercial, en consecuencia solo a estas últimas les fue aplicado el instrumento, el cual se realizó primero en Neiva y posteriormente en Pitalito y Garzón, con lo que se obtuvo, de primera mano, la información central que llevaría a determinar las posibles costumbres mercantiles que se han venido desarrollando en el sector inmobiliario desde hace varios años.

\section{ANÁLISIS DE LOS RESULTADOS}

Tras la ejecución de la metodología, tal como lo indica Latorre Iglesias y otros (2010), "para cuantificar la información de la encuesta, se realizó un conteo de las opciones seleccionadas en cada una de las preguntas; luego se aplicó el programa Excel para organizarlo y conocer los porcentajes de todas las respuestas" y así la existencia 0 inexistencia de costumbres mercantiles en el sector inmobiliario del departamento del Huila en relación con la intermediación en el arrendamiento de local comercial y la determinación del canon de arrendamiento a cobrar.

En relación con el primer objetivo, que describe los mecanismos establecidos por las inmobiliarias para fijar el valor del canon de arrendamiento del local comercial, se evidenció que el valor del canon de arrendamiento del local comercial, un $57 \%$ de las inmobiliarias dicen acordarlo con el propietario del inmueble arrendado, un 7\% dicen contratar los servicios de un avaluador, y un $36 \%$ dicen hacer uso de más de un mecanismo, contratan los servicios de un avaluador y/o llaman a averiguar por los inmuebles de similares características ubicados en la misma zona 0 acuerdan con el propietario del inmueble.

Cuadro $\mathbf{N}^{0}$ 1. Mecanismos establecidos por las inmobiliarias para fijar el valor del canon de arrendamiento de local comercial.

\begin{tabular}{lcc}
\hline \multicolumn{1}{c}{ Items } & $\begin{array}{c}\text { Frecuencia } \\
\text { absoluta }\end{array}$ & $\begin{array}{c}\text { Frecuencia } \\
\text { relativa }\end{array}$ \\
\hline $\begin{array}{l}\text { 1.Llamar a averiguar por los inmuebles que estén en arriendo en la misma zona y } \\
\text { con las mismas características. }\end{array}$ & 0 & $0 \%$ \\
\hline $\begin{array}{l}\text { 2. Consultar bases de datos en internet. } \\
\text { 3 Contratar los servicios de un avaluador. }\end{array}$ & 0 & $0 \%$ \\
$\begin{array}{l}\text { 4. Contratar los servicios de un avaluador o concertado con el propietario del } \\
\text { inmueble. }\end{array}$ & 2 & $7 \%$ \\
\hline $\begin{array}{l}\text { 5. Contratar los servicios de un avaluador y/o llamar a averiguar por los inmuebles } \\
\text { que estén en arriendo en la misma zona y con las mismas características }\end{array}$ & 3 & $14 \%$ \\
6. Concertado con el propietario del inmueble. & 8 & $22 \%$ \\
\hline TOTAL & 14 & $100 \%$ \\
\hline
\end{tabular}




\section{Gráfico № 1}

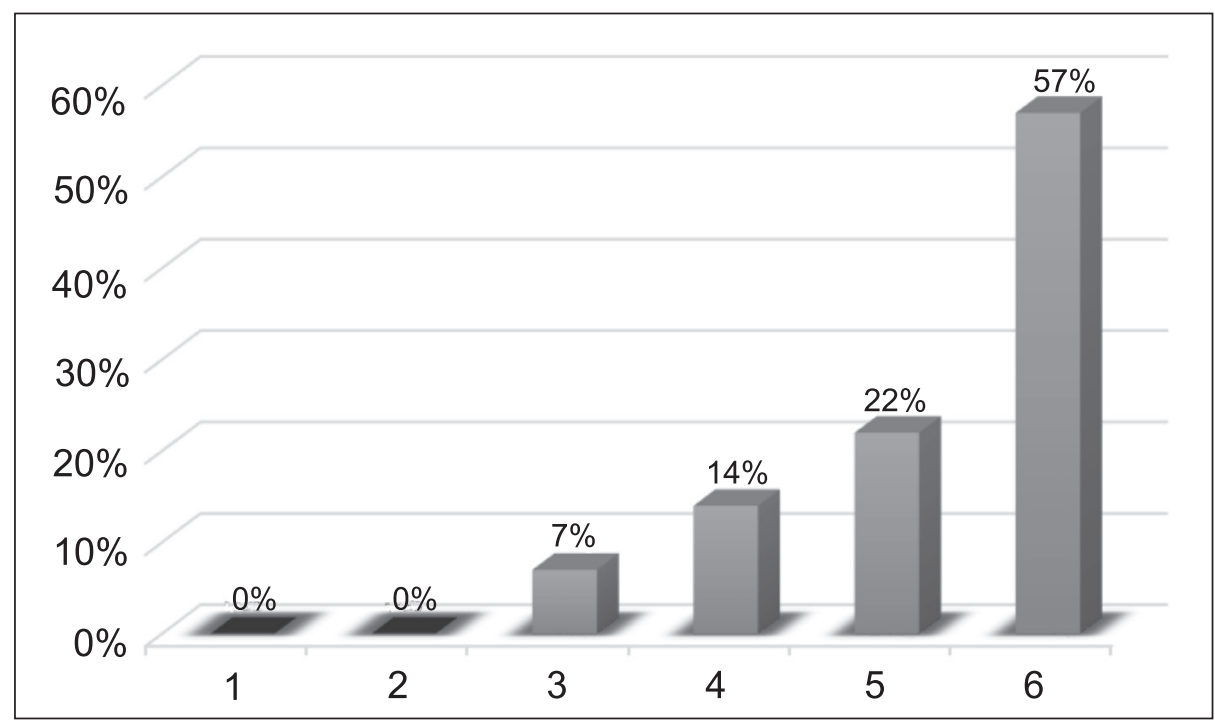

* Los números del grafico estadístico corresponden a cada uno de los ítems presentados en la tabla número 1.

En cuanto al incremento del canon de arrendamiento de local comercial, al igual que para la determinación del valor del canon de arrendamiento del mismo, las inmobiliarias hacen uso de diferentes mecanismos, un $43 \%$ lo acuerda con el propietario del bien inmueble, un 36\% lo determina con base al IPC, un $7 \%$ lo asigna, otro $7 \%$ manifiesta que es regla de una lonja de propiedad raíz y finalmente otro $7 \%$ lo acuerda tanto con el propietario del bien inmueble arrendado como con el arrendatario.

Cuadro $\mathbf{N}^{\circ}$ 2. Mecanismos establecidos por las inmobiliarias para fijar el incremento del valor canon de arrendamiento de local comercial.

Items

1. Es acordado por la inmobiliaria con el arrendatario.

2. Es regla de una lonja de propiedad raíz.

3. Impuesto por la inmobiliaria.

4. Es acordado por la inmobiliaria tanto con el propietario del bien inmueble arrendado como con el arrendatario.

5. El IPC.

6. Es acordado por la inmobiliaria con el propietario del bien inmueble arrendado. TOTAL

\section{Frecuencia Frecuencia absoluta relativa}

$0 \%$

0

$1 \quad 7 \%$

1

$7 \%$

1

$1 \%$

5

$36 \%$

6

$43 \%$

14 


\section{Grafica $N^{0} 2$}

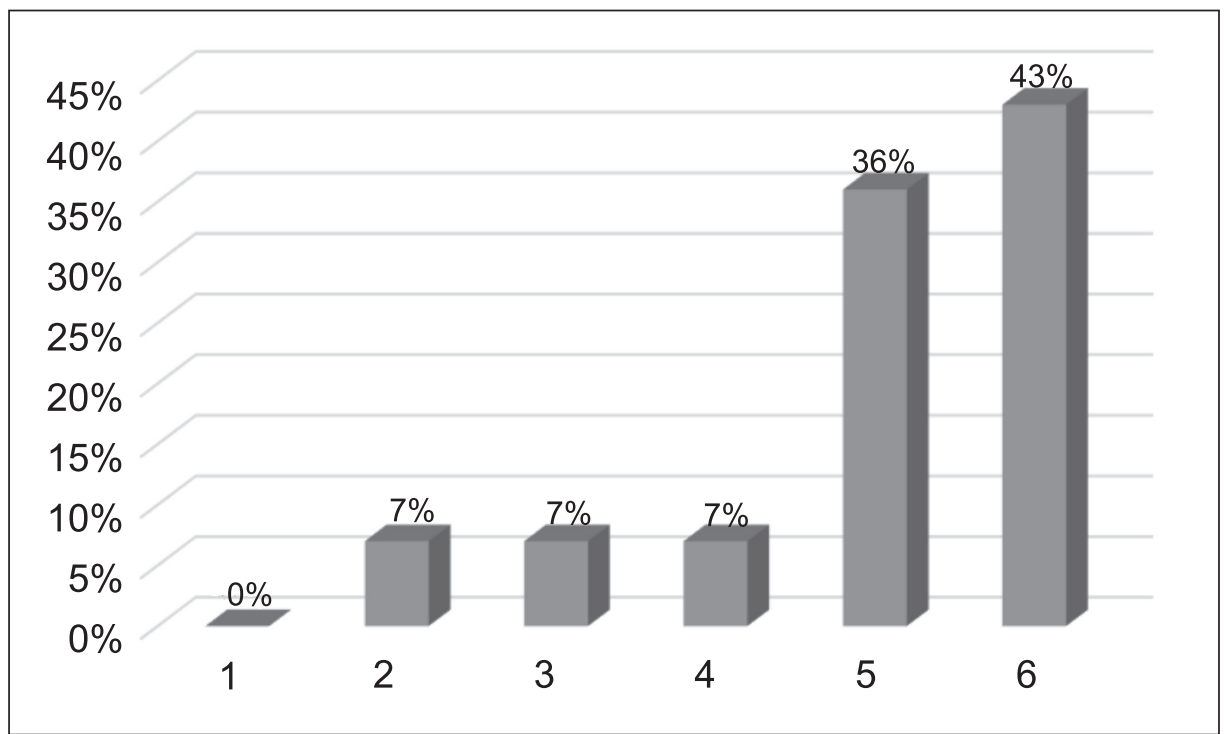

* Los números del grafico estadístico corresponden a cada uno de los ítems presentados en la tabla número 2.

En relación con el segundo objetivo, que busca definir el término utilizado por los agentes inmobiliarios o comisionistas para el pago del canon de arrendamiento al propietario del local comercial arrendado, se evidenció que el $93 \%$ de las inmobiliarias efectúan el pago del canon de arrendamiento al propietario del local comercial a mes anticipado y el $7 \%$ restante genera su pago a mes cumplido. Por tanto, esta práctica comercial cumple con los requisitos exigidos por la ley mercantil para ser considerada costumbre mercantil.

Cuadro $\mathbf{N}^{\circ}$ 3. Término empleado para el pago de los cánones de arrendamiento por la inmobiliaria al propietario del local comercial arrendado

\begin{tabular}{lcc}
\hline \multicolumn{1}{c}{ Items } & $\begin{array}{c}\text { Frecuencia } \\
\text { absoluta }\end{array}$ & $\begin{array}{c}\text { Frecuencia } \\
\text { relativa }\end{array}$ \\
\hline 1. Semestral & 0 & $0 \%$ \\
2. A acordar & 0 & $0 \%$ \\
3. A mes cumplido & 1 & $7 \%$ \\
4. A mes anticipado & 13 & $93 \%$ \\
TOTAL. & 14 & $100 \%$ \\
\hline
\end{tabular}




\section{Gráfico № 3}

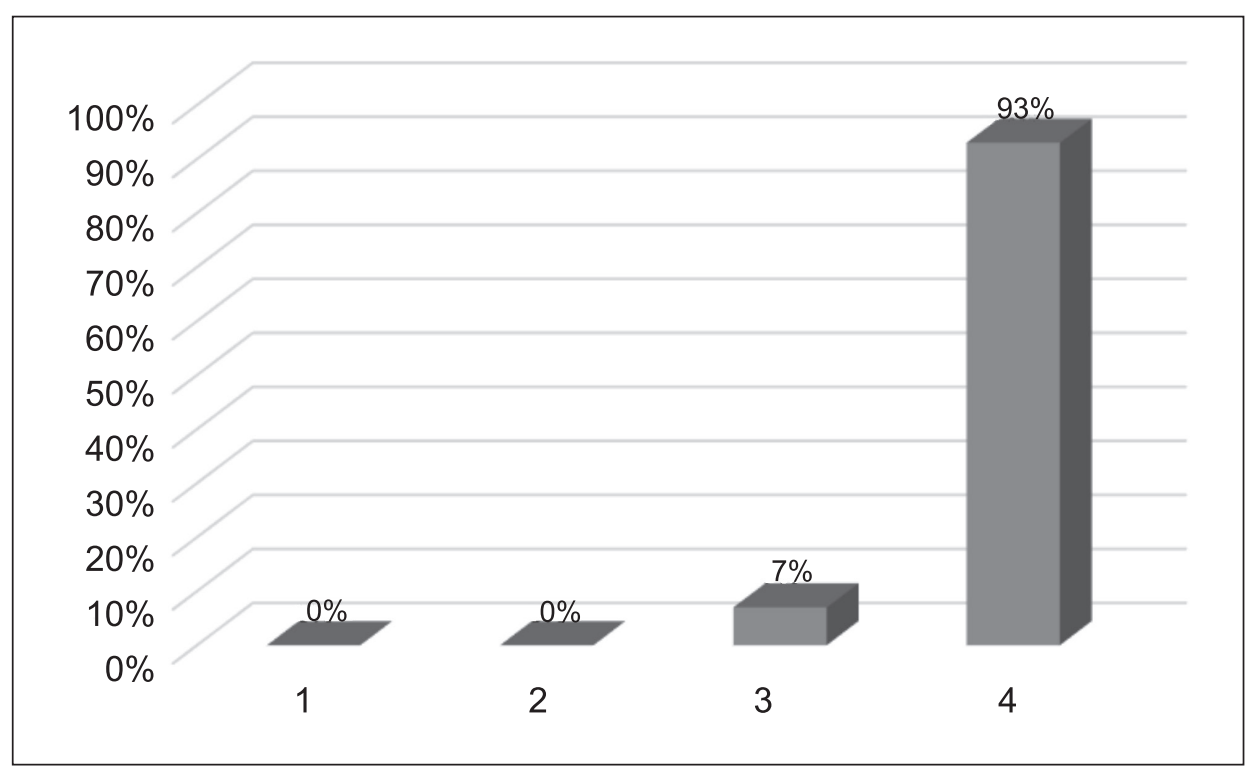

* Los números del grafico estadístico corresponden a cada uno de los ítems presentados en la tabla número 3.

En relación al tercer objetivo planteado, que se refiere al valor de la comisión por la intermediación en el arrendamiento de local comercial de acuerdo a las modalidades establecidas, se evidenció que la intermediación en el arrendamiento de local comercial, se presenta en dos modalidades:
- Intermediación en el arrendamiento de locales comerciales cuando estos no son entregados en administración.

- Intermediación en el arrendamiento de locales comerciales cuya administración les es conferida.

Cuadro № 4. Modalidades de arrendamiento de local comercial incorporadas por las inmobiliarias.

\section{Items}

1. La intermediación en el arrendamiento de locales comerciales cuando estos no son entregados en administración.

2. Todas las anteriores.

3. La intermediación en el arrendamiento de locales comerciales cuya administración le es conferida.

TOTAL
Frecuencia absoluta

0

3

11

14

\section{Frecuencia} relativa

$0 \%$

$21 \%$

$79 \%$ $100 \%$ 


\section{Gráfica Nº 4}

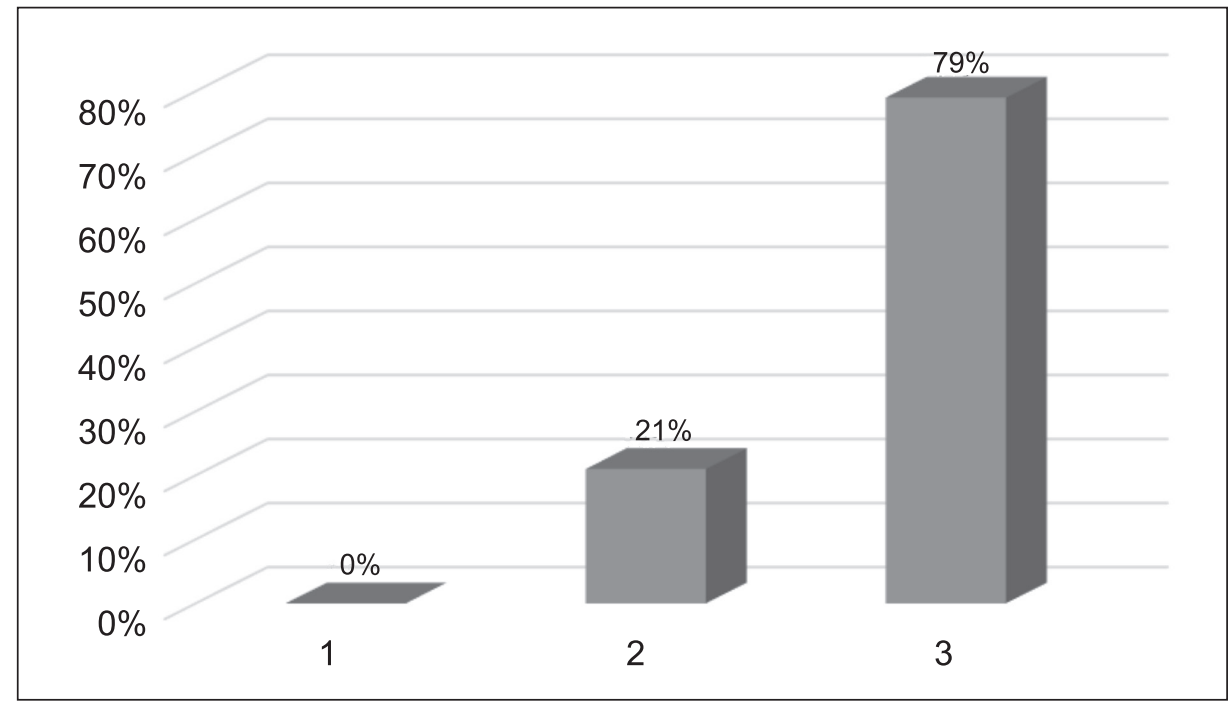

* Los números del grafico estadístico corresponden a cada uno de los ítems presentados en la tabla número 4.

En la primera modalidad, la intermediación en el arrendamiento de locales comerciales cuando estos no son entregados en administración, que en adelante se denominara de simple intermediación, el contrato suscrito entre el agente intermediario y el propietario del local comercial es el denominado Contrato de Corretaje consagrado en los artículos 1340 y siguientes del Código de Comercio.

En la segunda modalidad, la intermediación en el arrendamiento de locales comerciales cuya administración les es conferida, una de las operaciones inmobiliarias más frecuentes cómo es posible concluir al observar el Cuadro No. 1 puesto que el $100 \%$ de las inmobiliarias desarrollan esta modalidad, se está ante un contrato de corretaje que tiene por objeto la consecución de un contrato de arrendamiento, para subsiguiente entrega en calidad de administración, a través de un contrato de administración 0 de mandato (Bustos, 2006) puesto que mientras el $93 \%$ de las inmobiliarias encuestadas dicen suscribir con el propietario del local comercial arrendado un contrato de administración el 7\% restante por el contrario dicen suscribir un contrato de mandato.

Cuadro $\mathbf{N}^{\circ} \mathbf{5}$. Contrato suscrito entre el propietario del local comercial arrendado y la inmobiliaria.

\begin{tabular}{lcc}
\hline Items & $\begin{array}{c}\text { Frecuencia } \\
\text { absoluta }\end{array}$ & $\begin{array}{c}\text { Frecuencia } \\
\text { relativa }\end{array}$ \\
\hline 1. Consignación & 0 & $0 \%$ \\
\hline 2. Otro & 0 & $0 \%$ \\
3. Mandato & 1 & $7 \%$ \\
4. Administración & 13 & $93 \%$ \\
TOTAL & 14 & $100 \%$ \\
\hline
\end{tabular}




\section{Gráfica $N^{\circ} .5$}

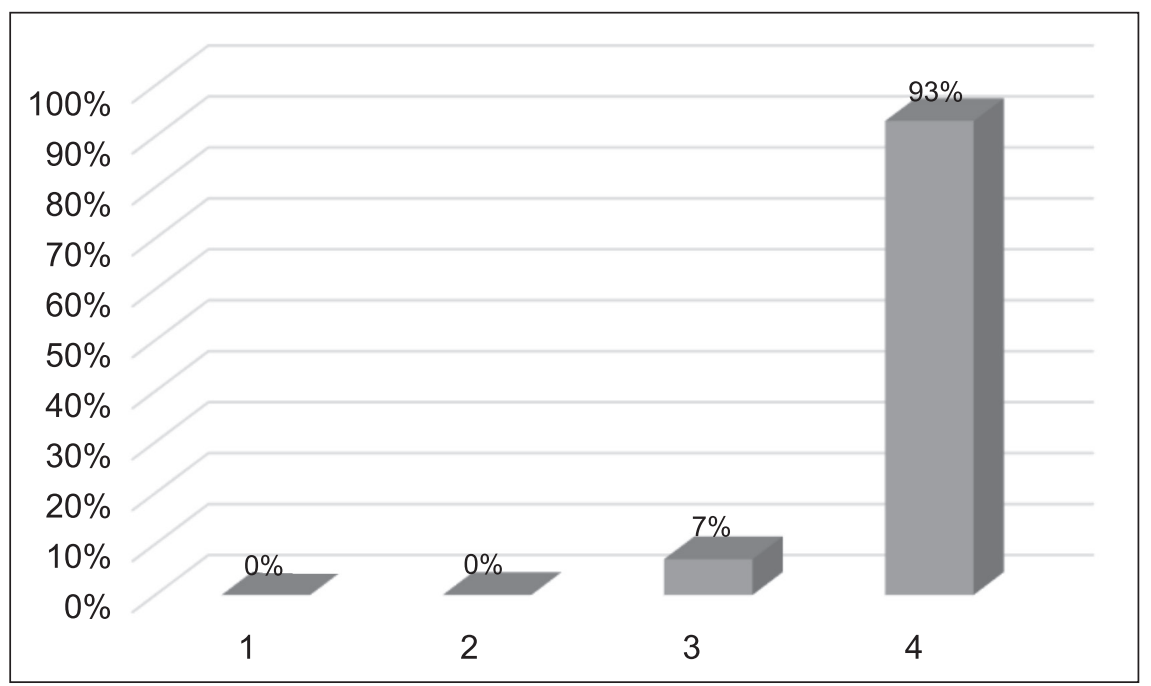

* Los números del grafico estadístico corresponden a cada uno de los ítems presentados en la tabla número 5.

En cuanto al derecho que implica la gestión que realiza el agente intermediario a recibir la remuneración estipulada por las partes, a falta de estipulación, el agente intermediario tendrá derecho a la remuneración usual, es decir, a la que se acostumbra generarse en el sector mercantil, para este caso, en el sector inmobiliario, y, en su defecto, a la que se fije por peritos (Art. 1341 del Código de Comercio). En departamento del Huila, el $100 \%$ de las inmobiliarias derivan el valor de la comisión por la intermediación en el arrendamiento de locales comerciales de un porcentaje del canon de arrendamiento.

Las inmobiliarias que desarrollan ambas modalidades de arrendamiento de locales comerciales, es decir, tanto la modalidad de simple intermediación como la modalidad de intermediación cuya administración les es conferida, aplican para cada modalidad el mismo porcentaje como valor de la comisión por la intermediación, del $5 \%$ al $10 \%$.
Cuadro $N^{0} 6$ y 6.1: Porcentaje del canon de arrendamiento como valor de la comisión por la intermediación aplicados por las inmobiliarias que desarrollan ambas modalidades de arrendamiento de local comercial.

\section{Cuadro $N^{\circ} 6$}

\begin{tabular}{lc}
\hline \multicolumn{1}{c}{ Item } & Numero de inmobiliarias \\
\hline 1. $5 \%-10 \%$ & 3 \\
\hline 2. $10 \%-15 \%$ & 0 \\
\hline 3. $15 \%-20 \%$ & 0 \\
4. $20 \%-25 \%$ & 0 \\
5. 0 tro & 0 \\
6. No aplica & 11 \\
\hline TOTAL. & 14 \\
\hline
\end{tabular}

Para once (11) de las catorce (14) inmobiliarias encuestadas no aplica esta pregunta por tener incorporada solo la modalidad de arrendamientos de local comercial cuya administración les es conferida, es decir, estas no desarrollan ambas modalidades. 
Por tanto, el 100\%, es decir, las tres (3) inmobiliarias que desarrollan el arrendamiento de locales comerciales tanto en la modalidad de simple intermediación como la modalidad de intermediación cuya administración les es conferida aplican para cada modalidad el mismo porcentaje como valor de la comisión por la intermediación.

Por el contrario las inmobiliarias que desarrollan exclusivamente la modalidad de intermediación cuya administración les es conferida en el arrendamiento de locales comerciales el porcentaje que derivan como valor de la comisión por la intermediación es el siguiente:
En las inmobiliarias de los municipios de Garzón y Pitalito, es decir, en un $30 \%$ de las inmobiliarias que en el departamento del Huila aplican esta modalidad, el valor de la comisión por dicha intermediación oscila entre $4 \%$ al $9 \%$ sobre el valor del canon de arrendamiento. Otro $30 \%$ de las inmobiliarias cobran el $10 \%$, un $10 \%$ generan un cobro que oscila entre el $5 \%$ al $10 \%$, otro $10 \%$ cobran el $10.2 \%$, otro $10 \%$ el $10,25 \%$ + IVA, y finalmente otro $10 \%$ generan un cobro que oscila entre el $10 \%$ al $15 \%$ sobre el valor del canon de arrendamiento.

Cuadro № 6.1.

\begin{tabular}{lcc}
\hline \multicolumn{1}{c}{ Items } & $\begin{array}{c}\text { Frecuencia } \\
\text { absoluta }\end{array}$ & $\begin{array}{c}\text { Frecuencia } \\
\text { relativa }\end{array}$ \\
\hline 1. $5 \%-10 \%$ & 3 & $100 \%$ \\
2. $10 \%-15 \%$ & 0 & $0 \%$ \\
3. $15 \%-20 \%$ & 0 & $0 \%$ \\
4. $20 \%-25 \%$ & 0 & $0 \%$ \\
5. Otro & 0 & $0 \%$ \\
\hline TOTAL. & 3 & $100 \%$ \\
\hline
\end{tabular}

\section{Gráfica № .6 .1}

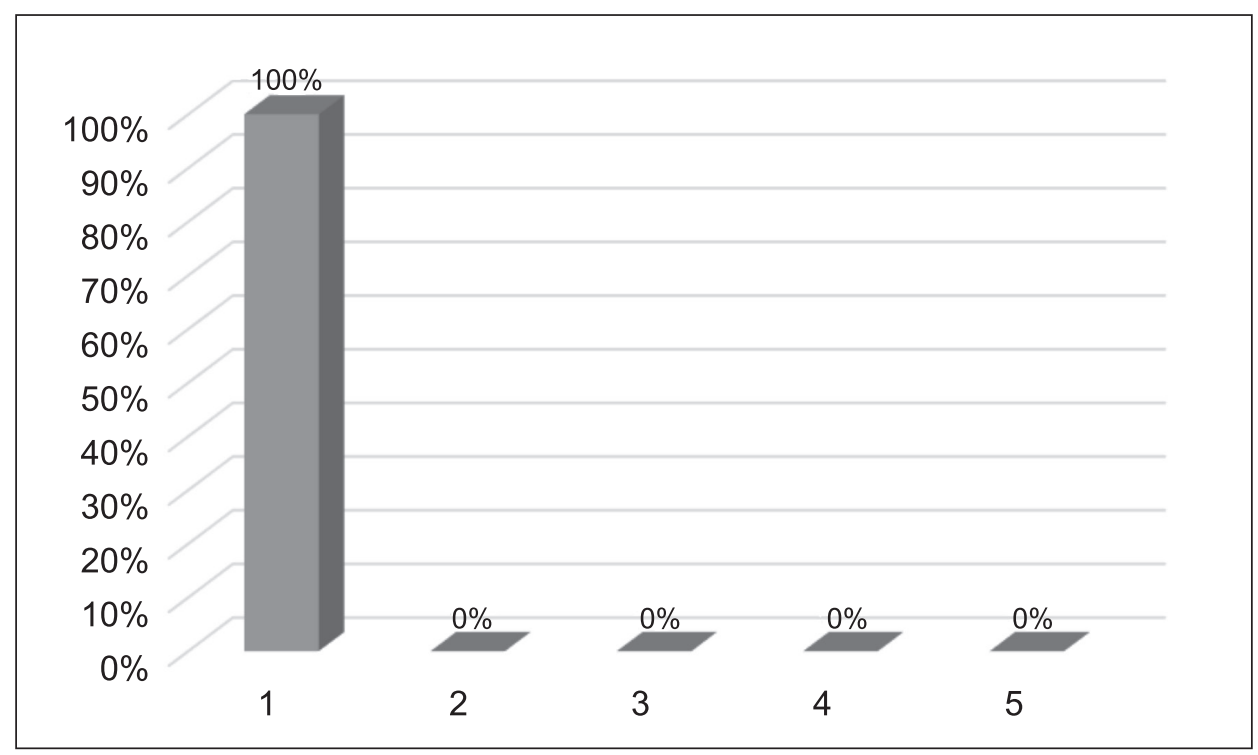

* Los números del grafico estadístico corresponden a cada uno de los ítems presentados en la tabla número 6.1. 
Para tres (3) de las inmobiliarias no aplica esta pregunta por cuanto, como ya se indicó tienen incorporada ambas modalidades de arrendamientos de locales comerciales y aplican en ambas el mismo porcentaje como valor de la intermediación sobre el costo del canon de arrendamiento. Por tanto, son once (11) el número de inmobiliarias de las cuales se conoce las respuestas por ser estas las que desarrollan exclusivamente la modalidad de intermediación en el arrendamiento de locales comerciales cuya administración les es conferida

Cuadro No. 7 y 7.1: Porcentaje del canon de arrendamiento como valor de la comisión por la intermediación en el arrendamiento de locales comerciales aplicados por las inmobiliarias que desarrollan exclusivamente la modalidad de intermediación cuya administración les es conferida.

\section{Cuadro $N^{0} 7$}

\begin{tabular}{lc}
\hline \multicolumn{1}{c}{ Respuestas } & Número de inmobiliarias \\
\hline 1. $4 \%-9 \%$ & 3 \\
2. $5 \%-10 \%$ & 1 \\
3. $10 \%$ & 3 \\
\hline 4. $10.2 \%$ & 1 \\
\hline 5. $10,25 \%+$ IVA & 1 \\
6. $10 \%-15 \%$ & 1 \\
\hline No aplica & 3 \\
\hline TOTAL & 14 \\
\hline
\end{tabular}

Cuadro $N^{0} .7 .1$

\begin{tabular}{lcc}
\hline \multicolumn{1}{c}{ Items } & $\begin{array}{c}\text { Frecuencia } \\
\text { absoluta }\end{array}$ & $\begin{array}{c}\text { Frecuencia } \\
\text { relativa }\end{array}$ \\
\hline 1. $4 \%-9 \%$ & 3 & $30 \%$ \\
\hline 2. $5 \%-10 \%$ & 1 & $10 \%$ \\
\hline 3. $10 \%$ & 3 & $30 \%$ \\
\hline 4. $10.2 \%$ & 1 & $10 \%$ \\
5. $10,25 \%+$ IVA & 1 & $10 \%$ \\
6. $10 \%$ a $15 \%$ & 1 & $10 \%$ \\
\hline TOTAL & 11 & $100 \%$ \\
\hline
\end{tabular}

\section{Gráfica № 7.1}

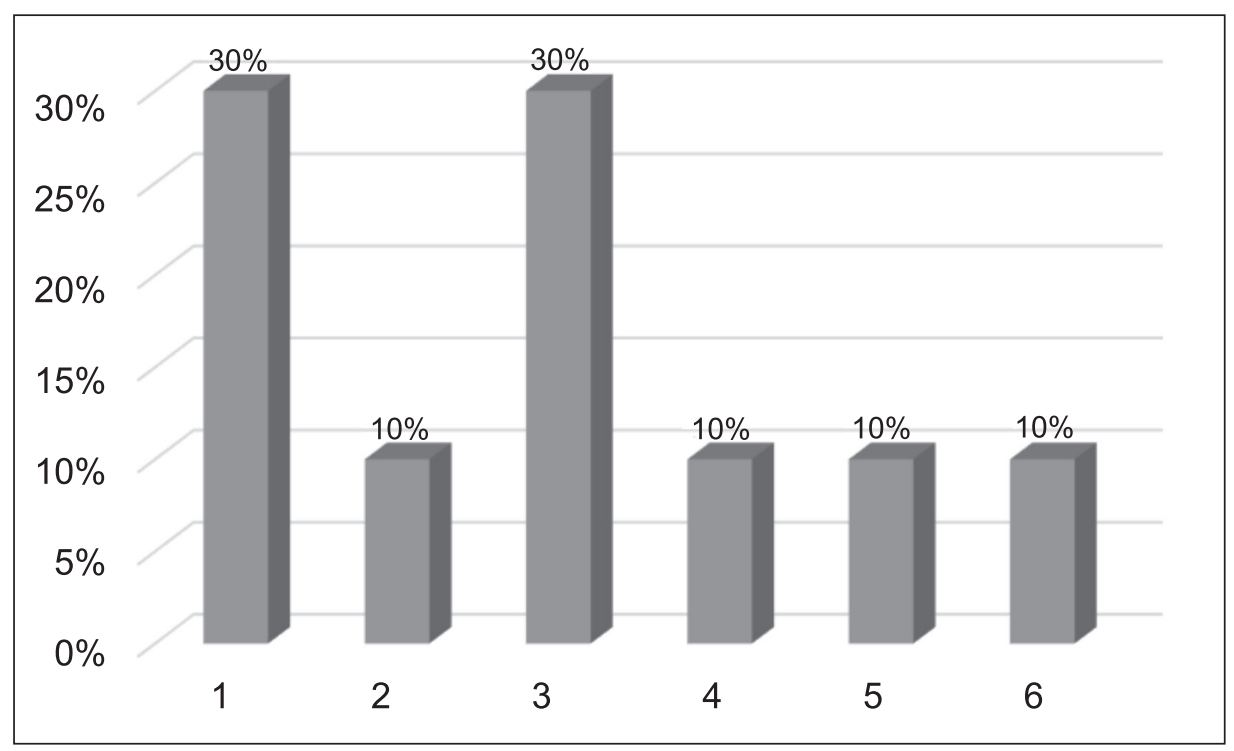

* Los números del grafico estadístico corresponden a cada uno de los ítems presentados en la tabla número 7.1. 
Finalmente, en cuanto a los mecanismosestablecidos para fijar al valor de la comisión por la intermediación en la celebración de contratos de arrendamiento de locales comerciales, cuando estos no son entregados en administración, un $67 \%$ de las inmobiliarias dicen acordarlo con el propietario del inmueble arrendado y un 33\% manifiesta que éste es regla de una lonja de propiedad raíz. En cuanto al valor de la comisión por la intermediación en la celebración del contrato de arrendamiento de locales comerciales cuya administración le es conferida, un $64 \%$ de las inmobiliarias lo acuerdan con el propietario del inmueble arrendado, un 22\% manifiestan que éste es regla de una lonja de propiedad raíz y finalmente un $14 \%$ de las inmobiliarias dicen imponerlo.

Cuadro No 8 y 8.1: Mecanismos establecidos para fijar el valor de la comisión por la intermediación en la celebración de contratos de arrendamiento de locales comerciales cuando estos no son entregados en administración.
Para 11 de las 14 inmobiliarias encuestadas no aplica esta pregunta por tener incorporada solo la modalidad de arrendamientos de local comercial cuya administración les es conferida, es decir, estas no desarrollan la modalidad de arrendamiento de local comercial de simple intermediación.

Por tanto, son tres (3) el número de inmobiliarias de las cuales se conocerán los mecanismos establecidos para fijar el valor de la comisión por la intermediación en la celebración de contratos de arrendamiento por ser éstas las que desarrollan además de la modalidad de intermediación en el arrendamiento de locales comerciales cuya administración les es conferida la modalidad de simple intermediación.

\section{Cuadro $N^{0} 8$}

\begin{tabular}{lc}
\hline \multicolumn{1}{c}{ Items } & Numero de inmobiliarias \\
\hline 1. Impuesto por la inmobiliaria. & 0 \\
2. Es regla de una lonja de propiedad raíz. & 1 \\
3. Es acordado por la inmobiliaria y el Propietario del inmueble arrendado & 2 \\
4. Es acordado por la inmobiliaria, arrendador y arrendatario & 0 \\
5. No aplica & 11 \\
TOTAL & 14 \\
\hline
\end{tabular}

\section{Cuadro No .8 .1}

\begin{tabular}{|c|c|c|}
\hline Items & Frecuencia absoluta & Frecuencia relativa \\
\hline 1. Impuesto por la inmobiliaria. & 0 & $0 \%$ \\
\hline $\begin{array}{l}\text { 2. Es acordado por la inmobiliaria, arrendador y } \\
\text { arrendatario }\end{array}$ & 0 & $0 \%$ \\
\hline 3. Es regla de una Ionja de propiedad raíz & 1 & $33 \%$ \\
\hline $\begin{array}{l}\text { 4. Es acordado por la inmobiliaria y el propietario del } \\
\text { inmueble arrendado. }\end{array}$ & 2 & $67 \%$ \\
\hline TOTAL & 3 & $100 \%$ \\
\hline
\end{tabular}




\section{Gráfica № 8.1}

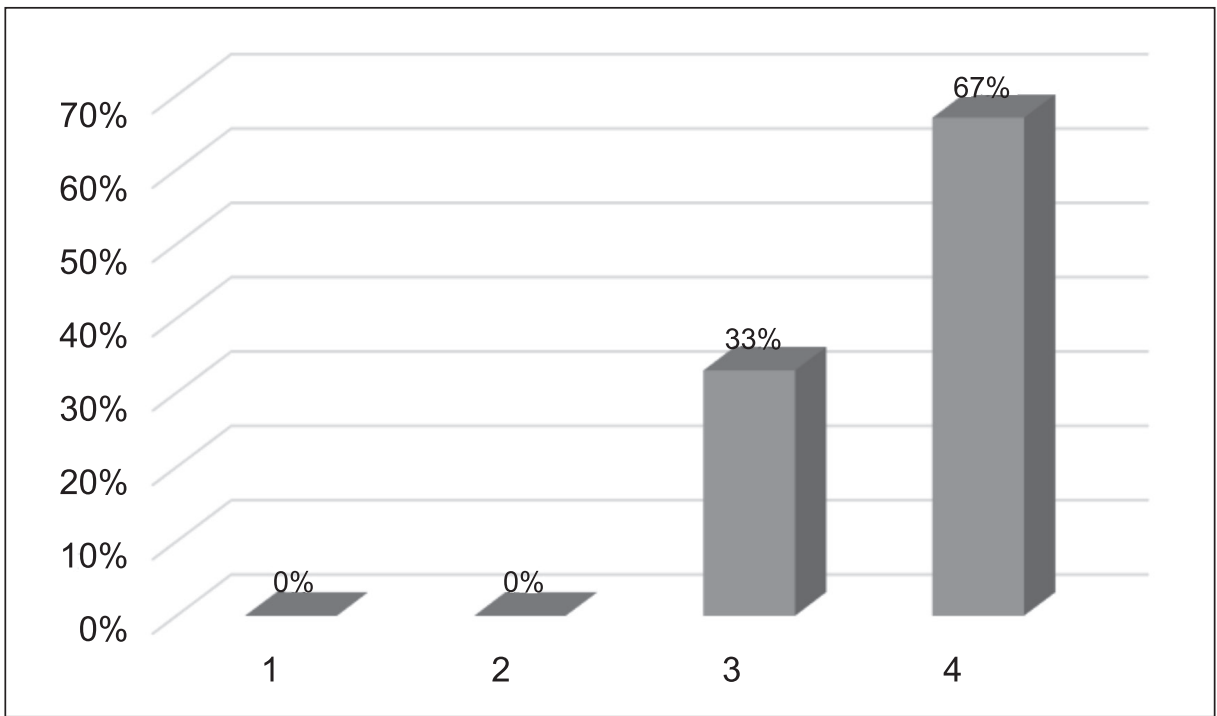

* Los números del grafico estadístico corresponden a cada uno de los ítems presentados en la tabla número 8.1.

Cuadro $\mathbf{N}^{0}$. 9: Mecanismos establecidos para fijar el valor de la comisión por la intermediación en la celebración de contratos de arrendamiento de locales comerciales cuya administración le es conferida.

\section{Items}

Frecuencia absoluta

1. Es acordado por la inmobiliaria, arrendador y arrendatario.

2. Impuesto por la inmobiliaria.

3. Es regla de una lonja de propiedad raíz.

4. Es acordado por la inmobiliaria y el propietario del inmueble arrendado.

TOTAL
0

$0 \%$

2

3

$14 \%$

$22 \%$

9

$64 \%$

14

$100 \%$ 


\section{Gráfica No. 9}

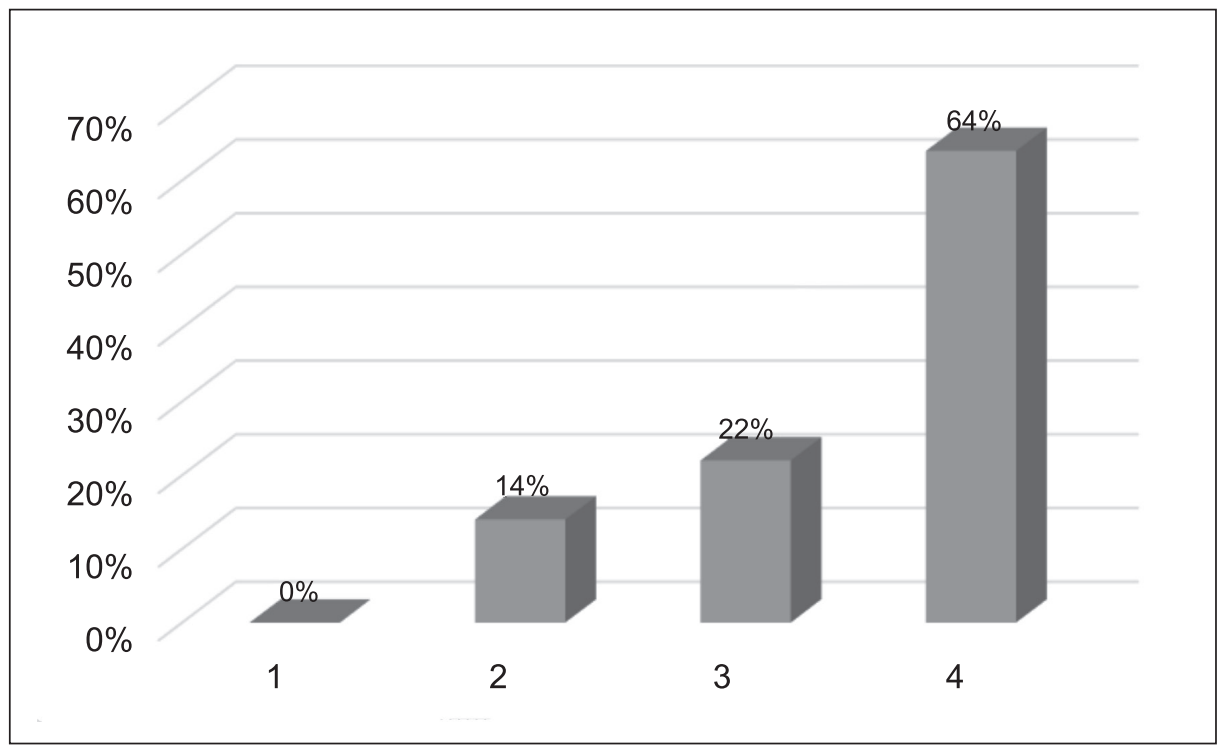

* Los números del grafico estadístico corresponden a cada uno de los ítems presentados en la tabla número 9.

Por tanto, de la práctica comercial analizada, como se evidencia en los datos anteriormente descritos, puede considerarse legalmente tan solo como costumbre mercantil tanto el contrato de administración, como clase de contrato suscrito entre el propietario del local comercial y la inmobiliaria, como el porcentaje del $5 \%$ al $10 \%$ sobre el valor del canon de arrendamiento como valor de la comisión por la intermediación en el arrendamiento de locales comerciales tanto en la modalidad de simple intermediación, como en la modalidad de intermediación cuya administración les es conferida cuando las inmobiliarias desarrollan ambas.

Con relación al cuarto objetivo "constitución del seguro inmobiliario para garantizar el pago del canon de arrendamiento del local comercial al propietario del mismo en caso de incumplimiento por parte del arrendatario", se determinó que en la actualidad, de acuerdo con los resultados observados, el 100\% de las inmobiliarias no exigen la constitución de un seguro inmobiliario para garantizar el pago del canon de arrendamiento de local comercial al propietario del mismo en caso de incumplimiento por parte del arrendatario por cuanto en el departamento del
Huila, no existe una aseguradora que ofrezca tal servicio.

Ante la imposibilidad de exigir la constitución de un seguro, las inmobiliarias han recurrido a la exigencia del depósito como "garantía" para arrendar el inmueble; y al no obtener el resultado deseado en esta primera pregunta de las creadas para establecer la existencia o inexistencia de esta práctica mercantil, es evidente que las demás ya no tienen aplicación ni valor alguno.

\section{CONCLUSIONES}

En la búsqueda de la información tal como lo indica Latorre Iglesias y otros (2010), se halló que "muchas de las inmobiliarias que figuraban en la base de datos de Cámara de Comercio, se inscribían como tales, pero al mirar las actividades que realizaban, no se dedicaban a prácticas del sector, 0 a pesar de seguir en esa base de datos, ya no existían.

De las sesenta y tres (63) inmobiliarias que figuraban en la base de datos de Camara de Comercio, se encontró, al corroborar la información para programar las visitas para la aplicación del 
instrumento elaborado que realmente habían tan solo doce (12) inmobiliarias en la ciudad de Neiva, cuatro (4) en el municipio de Pitalito y una (1) en el municipio de Garzón, debido a que la mayoría habían desaparecido del mercado, se habían trasladado a otras ciudades o simplemente la dirección no existía 0 de existir correspondía a una vivienda u otro tipo de negocio. Es decir, aproximadamente un $70 \%$ son construcciones de papel. Lo cual desde un primer momento de esta investigación, nos llevó a vislumbrar la falta de organización y de control del sector.

De las diecisiete (17) inmobiliarias que existen en la práctica, tres (3) no tienen incorporada la modalidad de arrendamiento de local comercial; de las catorce (14) restantes que por el contrario si tienen incorporada dicha modalidad desde la constitución de las mismas, once (11) desarrollan exclusivamente la intermediación en el arrendamiento de locales comerciales cuya administración les es conferida y tres (3) desarrollan tanto la intermediación en el arrendamiento de locales comerciales cuya administración les es conferida como la simple intermediación. Para las agencias inmobiliarias huilenses es más viable económicamente desarrollar la ultima intermediacion en mención (intermediación en el arrendamiento de locales comerciales cuya administración), en razón a que constituye un flujo de caja constante.

Local comercial ha de entenderse como bodega, oficina o lugar de establecimiento de comercio por haber sido así definido por las inmobiliarias encuestadas.

De las prácticas comerciales del sector inmobiliario analizadas, puede considerarse legalmente tan solo como costumbre mercantil el término utilizado por los agentes inmobiliarios o comisionistas para el pago del canon de arrendamiento al propietario del bien inmueble, a mes anticipado, dentro del valor de la comisión por la intermediación en el arrendamiento de local comercial de acuerdo con las modalidades establecidas, el contrato de administración, como clase de contrato suscrito entre el propietario del local comercial y la inmobiliaria, como el porcentaje del $5 \%$ al $10 \%$ sobre el valor del canon de arrendamiento como valor de la comisión por la intermediación en el arrendamiento de locales comerciales tanto en la modalidad de simple intermediación como en la modalidad de intermediación cuya administración les es conferida cuando las inmobiliarias desarrollan ambas.

En el departamento del Huila, no existe una aseguradora que ofrezca el servicio del seguro inmobiliario, con el cual se garantice el pago del canon de arrendamiento al propietario en caso de incumplimiento por parte del arrendador. Vacío en materia de seguros que ha llevado a que algunas inmobiliarias recurran a la exigencia de la constitución de depósitos como "garantía" a los posibles arrendatarios para que se pueda elaborar y ejecutar el contrato de arrendamiento.

\section{REFERENCIAS BIBLIOGRÁFICAS}

- Bustos Zalamea, M., Fonseca Ulloa, J. \&Velásquez Melo V (2006). La Costumbre Mercantil en la Actividad Inmobiliaria. Bogotá D.C.: Sello Editorial Lonja de Propiedad Raíz de Bogotá.

- Espinosa Pérez, C. (2000). Del uso convencional a la costumbre mercantil como norma jurídica. Revista de Derecho Privado, No. 25.

- Garrigues Díaz, J (1971). Hacia un nuevo derecho mercantil. Madrid: Tecnos.

- Latorre Iglesias, E. \& otros (2010). La Costumbre Mercantil Aspectos Turísticos e Inmobiliarios, Bogotá D.C.: Universidad Sergio Arboleda.

- Peña Castrillón, G. (1983). El derecho comercial frente al derecho civil en los planes de revisión del código civil colombiano. Bogotá D.C.: Gráficas Fepar.

- Pinzón, J. (1961). Introducción al derecho comercial. Bogotá D.C.: Temis.

- Santos Pinzón, D. (2009). La Costumbre Mercantil. Dosquebradas: Cámara de Comercio de Dosquebradas.

- Silva Nigrinis, M. (2007). La Costumbre Mercantil en la Actividad Inmobiliaria. Bogotá D.C.: Lonja de propiedad raíz de Bogotá. 
- Cámara de Comercio de Bogotá (1985). Revista Cámara de Comercio de Bogotá, № 56, 37.

- Cámara de Comercio de Bogotá (1989). Revista Cámara de Comercio de Bogotá, № 73, 27 - 29, 35.

- CámaraDeComercioDelpiales,(2008).Costumbre Mercantil. Comisión por Intermediación en la Compraventa de Bienes Inmuebles y Vehículos Automotores. Ipiales: Cámara de Comercio de Ipiales.

- Cámara de Comercio de Bogotá (2009). Ensayos de Costumbre Mercantil; Bogotá D.C.: Fundación Universitaria Empresarial de la Cámara de Comercio de Bogotá - Uniempresarial (Colombia), Cámara de Comercio de Bogotá.

\section{REFERENCIAS JURISPRUDENCIALES}

\section{Corte Constitucional}

- CConst, C-486/1993, E. Cifuentes.

- CConst, C-224/1994, A. Mejia

- CConst, T-537/2009, H. Sierra.

- CConst, T-117/ 2011, H Sierra.

\section{Corte Suprema de Justicia CSJ}

- CSJ Civil, 9 Julio. 2011, E. Villamil.

- CSJ Civil, 14 Abril.2008, W. Namén.

- CSJ Civil, 24 Septiembre.2001, J Ramírez.

- CSJ Civil, 27 Marzo.1998, J Ramírez.

\section{Consejo de Estado}

- CE expediente No. 14330, R. Hoyos.

- Normativas

D. $410 / 1971$. 